\title{
Water Absorption and Diffusion Characteristics of Nanohydroxyapatite (nHA) and Poly(hydroxybutyrate-co-hydroxyvalerate-) Based Composite Tissue Engineering Scaffolds and Nonporous Thin Films
}

\author{
Naznin Sultana ${ }^{1,2}$ and Tareef Hayat Khan ${ }^{3}$ \\ ${ }^{1}$ Department of Mechanical Engineering, The University of Hong Kong, Pokfulam Road, Hong Kong \\ ${ }^{2}$ IJN-UTM Cardiovascular Engineering Centre (CEC), Faculty of Biosciences and Medical Engineering, Universiti Teknologi Malaysia, \\ 81310 UTM Johor Bahru, Johor, Malaysia \\ ${ }^{3}$ KALAM, Faculty of Built Environment, Universiti Teknologi Malaysia, 81310 UTM Johor Bahru, Johor, Malaysia
}

Correspondence should be addressed to Naznin Sultana; naznin@biomedical.utm.my

Received 15 March 2013; Revised 10 April 2013; Accepted 10 April 2013

Academic Editor: In-Kyu Park

Copyright (C) 2013 N. Sultana and T. H. Khan. This is an open access article distributed under the Creative Commons Attribution License, which permits unrestricted use, distribution, and reproduction in any medium, provided the original work is properly cited.

\begin{abstract}
Water uptake characteristics of poly(hydroxybutyrate-co-hydroxyvalerate) (PHBV-) based composite tissue engineering (TE) scaffolds incorporating nanosized hydroxyapatite (nHA) have been investigated. The water absorption of these composite scaffolds obeyed the classical diffusion theory for the initial period of time. The diffusion coefficients of the composite scaffolds during the water absorption were much faster than those for the nonporous thin films, suggesting that the water uptake process depends on the presence of porosity and porous microstructure of the composite scaffolds. The incorporation of nHA increased the water uptake of both the composite scaffolds and thin films. It was also observed that the equilibrium uptake increased with the incorporation of nHA. This increase in the water uptake was largely due to the nHA particle aggregates in the microstructure of both composite scaffolds and thin films. The activation energy for diffusion was also determined using the Arrhenius equation for both porous scaffolds and thin films and the results suggested that the activation energy for scaffolds was lower than that for thin films.
\end{abstract}

\section{Introduction}

Through the combination of cell biology, biomaterials, and engineering, tissue engineering (TE) seeks to provide a solution to replace, repair, or regenerate tissues/organs $[1$, 2]. To overcome the limitations of the autogenous and allogenic bone graft, development of new synthetic scaffolds has received increasing interest. In TE, the biomaterial based scaffolds are the most important aspects [3, 4]. A number of approaches such as phase separation, selective laser sintering, and electrospinning are being used for fabricating scaffolds for bone regeneration. Biodegradable polymers, including poly(caprolactone), poly(l-lactic acid) (PLLA), and poly(hydroxybutyrate-co-hydroxyvalerate) (PHBV), have been processed into 3D scaffolds with the development of TE [5].
Both PLLA and PHBV possess good biocompatibility with tissue and blood and are regarded as good candidates as biodegradable polymer matrix of composite scaffolds [6]. Blending of PHBV with PLLA can shorten the degradation time and rate of PHBV which has much longer degradation time $[7,8]$. Several biodegradable polymer-hydroxyapatite (HA) composites have been developed as bone substitute material or bone TE scaffolds [9-11]. As HA is a natural component of bones and possesses the osteoconductive properties, polymer-HA composite scaffold is a promising system for bone tissue regeneration as it can mimic the composition and structure with the mineral phase of the bone.

By guiding new tissue growth in vivo and in vitro, scaffolds play an important role in TE. The scaffolds possess 3D macroporous and interconnected network with 
the macropore diameter of a few hundreds of micrometers to allow cell invasion. The water uptake properties of composite scaffolds for tissue TE are of importance as the primary mechanism of the polymer degradation inside body is hydrolysis. The ingress of water into polymer-based scaffolds can have both adverse and beneficial effects on the properties of the scaffolds. Hydrolysis and microcrack can be formed due to water exposure. On the other hand, breakdown of three-dimensional scaffolds can occur due to excessive water uptake. Several studies have been performed for dental application to study the characteristics of polymeric systems and composites $[12,13]$. However, the water uptake and diffusion characteristics of TE scaffolds have been rarely assessed and reported.

Previously, we reported the fabrication, characterization, and in vitro biological evaluation of PHBV/PLLAbased scaffolds [14]. The aim of the present study was to determine the water uptake and diffusion characteristics of 100/0 PHBV/PLLA, 50/50 PHBV/PLLA blend, and 10\% nHA incorporated 50/50 PHBV/PLLA composite scaffolds. For comparison, solvent-cast thin films were also used in the study. The effect of incorporation of HA, porosity, and microstructures of the composite scaffolds on the diffusion coefficient, equilibrium uptake, and temperature dependence was also investigated.

\section{Experimental}

2.1. Materials and General Methods. PHBV with 6\% of 3hydroxyvalerate was purchased from Sigma-Aldrich. In order to blend with PHBV, PLLA with viscosity $1.6 \mathrm{dL} \mathrm{g}^{-1}$ (Medisorb 100L 1A) was purchased from Lakeshore Biomaterials (Birmingham, AL). The nHA nanoparticles were produced in-house which were used for producing composite scaffolds and composite thin films [15]. Figure 1 shows the SEM micrograph of nanosized HA. The freeze-dried HA powders used in this investigation consisted of tiny agglomerates of HA nanocrystallites. The particle size of the HA powders was found to be in the range of $20-30 \mathrm{~nm}$. Chloroform and acetic acid were analytical grade.

2.2. Fabrication of Scaffolds and Solvent Cast Films. Pure 100/0 PHBV/PLLA, 50/50 PHBV/PLLA, and 10\% nHA in 50/50 PHBV/PLLA tissue engineering scaffolds with $10 \%$ $(\mathrm{w} / \mathrm{v})$ polymer concentration were fabricated using the emulsion freezing/freeze-drying technique described elsewhere [16]. Briefly, to produce polymer scaffolds, $1 \mathrm{~g}$ polymer or polymer blend was dissolved in $5 \mathrm{~mL}$ chloroform and then $5 \mathrm{~mL}$ acetic acid was added. The emulsion was then homogenized and kept frozen at $-18^{\circ} \mathrm{C}$ in a freezer for overnight to induce phase separation. Then the frozen emulsion was freeze-dried using a freeze-drying vessel (Labconco, USA). Similarly, to produce $10 \% \mathrm{nHA}$ in 50/50 PHBV/PLLA composite scaffolds, $0.1 \mathrm{~g}$ nHA was added in the emulsion and homogenized prior to the phase-separation process. Nonporous thin films with the same compositions were fabricated using solvent casting technique.

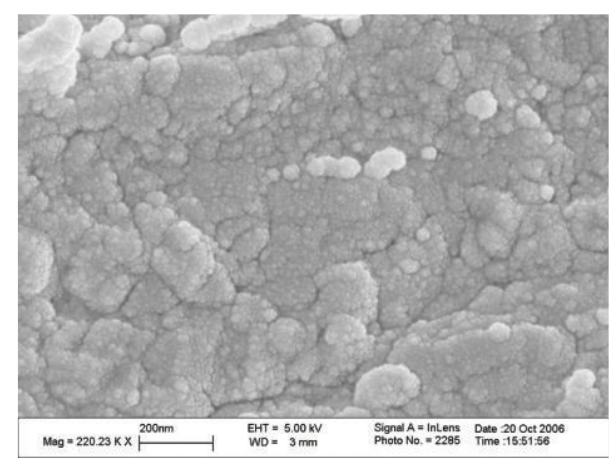

FIGURE 1: SEM micrograph of nanosized HA particles synthesized in-house through a nanoemulsion process.

2.3. Preparation of Polymer and Composite Specimens. Rectangular shape specimens $(20 \mathrm{~mm} \times 5 \mathrm{~mm} \times 0.5 \mathrm{~mm})$ were cut with sharp razor blade from three types of polymer and composite scaffolds, namely, PHBV scaffolds (10\% w/v), 50/50 PHBV/PLLA (10\% w/v) blend scaffolds, and 10\% nHA in PHBV/PLLA $(10 \% \mathrm{w} / \mathrm{v})$ composite scaffolds. Rectangular specimens of $(20 \mathrm{~mm} \times 5 \mathrm{~mm} \times 0.5 \mathrm{~mm})$ were also prepared from solvent-cast films of the same compositions. The porous microstructure, morphology, and pore sizes of the scaffolds specimens were studied using a scanning electron microscopy (SEM; Stereoscan 440, UK). In order to determine the presence and distribution of $\mathrm{nHA}$ nanoparticles in composite scaffolds, energy dispersive X-ray spectrometry (EDX, INCA 300, UK) was performed. The skeletal density and the porosity of the scaffolds were measured using equations described elsewhere [16]. The wettability of the scaffolds was measured by measuring contact angles using a contact angle measuring machine (SL200B, Shanghai Salon Tech Inc., Ltd., China). With distilled water as liquid, the sessile drop method was employed. The contact angle of the water drop on the scaffold specimen was determined at room temperature using proprietary software. At least three measurements were conducted at different locations of the scaffold specimen. As the mean \pm standard deviation, the contact angle was expressed.

2.4. Water Absorption. The specimens were placed in an oven at $37^{\circ} \mathrm{C}$ for 48 hours and then weighed to an accuracy of $\pm 0.0001 \mathrm{~g}$ on a balance. The specimens were then placed into $100 \mathrm{~mL}$ of distilled water at $37^{\circ} \mathrm{C}$. During the first day of immersion, the specimens were removed at intervals of 2 , $5,10,15 \mathrm{~min}$, and so forth, blotted dry on filter paper to remove excess water, weighed, and returned to the water. Following the first day, the samples were weighed daily, until the uptake slowed. Until there was no significant change in weight, the uptake of water was recorded. When equilibrium was attained, the samples were then transferred to a drying oven at $37^{\circ} \mathrm{C}$. Similarly, the experiment was repeated at $25^{\circ} \mathrm{C}$ and at $50^{\circ} \mathrm{C}$. 
2.5. Diffusion Coefficients. For the earlier stages of uptake (usually where $M_{t} / M_{\infty} \leq 0.5$ ), classical diffusion theory predicts $[1,17]$ the following:

$$
\frac{M_{t}}{M_{\infty}}=2\left(\frac{D t}{\pi l^{2}}\right)^{1 / 2}
$$

where $M_{t}$ is the mass uptake at time $t, M_{\infty}$ is the mass uptake at equilibrium, $2 l$ is the thickness of the specimen, $D$ is the diffusion coefficient, and $t$ is the water uptake time. A plot of $M_{t} / M_{\infty}$ against $t^{1 / 2}$ should provide a straight line for earlier stages of water uptake. Diffusion coefficients can be calculated from the slope of the straight line.

The temperature dependence of the diffusion coefficient is given by the Arrhenius equation:

$$
\ln D=\ln D_{0}-\frac{Q}{R}\left(\frac{1}{T}\right)
$$

where $T$ is the absolute temperature $\left({ }^{\circ} \mathrm{K}\right), \mathrm{Q}$ is the activation energy for diffusion ( $\mathrm{J} / \mathrm{mol}$ or $\mathrm{eV} /$ atom), and $D_{o}$ is a temperature independent constant (preexponential) $\left(\mathrm{m}^{2} / \mathrm{s}\right), R$ is the gas constant $\left(8.314 \mathrm{~J} / \mathrm{mol}-\mathrm{K}\right.$ or $8.62 \times 10^{-5} \mathrm{eV} /$ atom $)$.

\section{Results and Discussion}

Several assumptions were used for this study. They were as follows.

(i) Distilled water was in infinite supply.

(ii) Polymer and composite films and scaffolds were surrounded by water.

3.1. Morphological Observation. Figure 2 shows the morphologies of thin films of 100/0 PHBV/PLLA, 50/50 PHBV/PLLA, and $10 \%$ nHA incorporated 50/50 PHBV/PLLA. Some micropores were observed in 50/50 PHBV/PLLA thin film due to the immiscibility of PHBV and PLLA. Figure 3 shows the morphologies of 100/0 PHBV/PLLA, 50/50 PHBV/PLLA, and $10 \% \mathrm{nHA}$ in 50/50 PHBV/PLLA scaffolds. It was observed that highly porous scaffold specimens consisted of many micropores. Pore structure and size depended on the phase separation process used in the fabrication technique. Scanning electron microscopy (SEM) and energy dispersive $\mathrm{X}$-ray spectroscopy showed the distribution of HA nanoparticles in the pore walls of the scaffolds, and some particle agglomeration was also observed (Figure 4). The average pore diameter of the 100/0 PHBV/PLLA scaffold was higher than that of $10 \%$ nHA incorporated 50/50 PHBV/PLLA scaffold as incorporation of $\mathrm{nHA}$ perturbed the phase separation process slightly (Table 1). As the scaffolds were prepared from same polymer emulsion concentration, $10 \%(\mathrm{w} / \mathrm{v})$, the porosity did not change significantly in the scaffolds. The contact angle was much higher in 100/0 PHBV/PLLA scaffold than 50/50 PHBV/PLLA and 10\% nHA in PHBV/PLLA scaffolds as PHBV polymer is well known for its hydrophobic nature. Blending with PLLA and incorporporation of $\mathrm{nHA}$ increased the hydrophilicity of the composite scaffolds.
TABLE 1: Average pore diameter, porosity, and contact angle of the scaffold.

\begin{tabular}{lccc}
\hline Scaffold & $\begin{array}{c}\text { Average pore } \\
\text { diameter }(\mu \mathrm{m})\end{array}$ & Porosity \% & $\begin{array}{c}\text { Contact } \\
\text { angle }\end{array}$ \\
\hline 100/0 PHBV/PLLA & 290 & $75 \pm 2.0$ & $103 \pm 1.6$ \\
50/50 PHBV/PLLA & 271 & $77 \pm 1.5$ & $98 \pm 2.5$ \\
10\% nHA in 50/50 & 250 & $72 \pm 3.0$ & $83 \pm 1.5$ \\
PHBV/PLLA & & & \\
\hline
\end{tabular}

3.2. Diffusion Study of Solvent-Cast Thin Films. Figure 5 shows the water uptake curve of $100 / 0$ PHBV/PLLA thin film at $37^{\circ} \mathrm{C}$ as $M_{t} / M_{\infty}$ versus the square root of immersion time. The specimens were immersed in distilled water. The maximum uptake at equilibrium was $1.4 \%$. The diffusion coefficients were calculated from the initial linear region of the curves.

In order to observe the temperature dependence of the diffusion coefficients of $100 / 0$ PHBV/PLLA thin film, the experiment was performed at three different temperatures, namely, at $25^{\circ} \mathrm{C}, 37^{\circ} \mathrm{C}$, and $50^{\circ} \mathrm{C}$. Water uptake study was also performed for 50/50 PHBV/PLLA thin film and 10\% HA in 50/50 PHBV/PLLA thin film following the same procedure mentioned above. The calculated diffusion coefficients are given in Table 2. It can be seen that diffusion coefficient is significantly higher at high temperature of $50^{\circ} \mathrm{C}$ than that of $25^{\circ} \mathrm{C}, 37^{\circ} \mathrm{C}$.

In order to study the temperature dependence of diffusion coefficients, Arrhenius plot was constructed for 10\% HA in 50/50 PHBV/PLLA thin films as shown in Figure 6. From the slope of the curve, activation energy can be calculated which is referred to as the energy required to produce the diffusive motion of one mole of atoms. The activation energy calculated from the slope of the best fit linear curve was $76 \pm 20 \mathrm{KJ} / \mathrm{mole}$ with the regression coefficient, $r^{2}$ value of 0.94. The activation energy of 100/0 PHBV/PLLA and 50/50 PHBV/PLLA thin film was $99.8 \pm 21.9 \mathrm{KJ} /$ mole and $112 \pm$ $45 \mathrm{KJ} / \mathrm{mole}$, respectively.

3.3. Diffusion Study of Scaffolds. Figure 7 is the plot of water uptake as $M_{t} / M_{\infty}$ versus square root of immersion time at $37^{\circ} \mathrm{C}$ for $100 / 0$ PHBV/PLLA scaffolds. The diffusion coefficients were calculated from the initial linear regions of the curves. In order to study the temperature dependence of diffusion coefficients of the scaffolds, the experiment was performed at three different temperatures, namely, at $25^{\circ} \mathrm{C}$, $37^{\circ} \mathrm{C}$, and $50^{\circ} \mathrm{C}$.

Table 3 shows the diffusion coefficients of 100/0 PHBV/ PLLA scaffolds at $25^{\circ} \mathrm{C}, 37^{\circ} \mathrm{C}$, and $50^{\circ} \mathrm{C}$, which were $51.75 \times$ $10^{-12}, 67.60 \times 10^{-12}$, and $165 \times 10^{-12} \mathrm{~m}^{2} / \mathrm{s}$, respectively. It was observed that the initial water uptake of HA incorporated composite scaffold was much higher than that of polymer blend scaffolds, and the diffusion coefficients were also higher. The value of diffusion coefficient was lower at low temperature and relatively high at high temperature. Figure 8 shows the Arrhenius plot which represents the temperature dependence of the diffusion coefficients of $10 \% \mathrm{HA}$ in 50/50 PHBV/PLLA scaffolds. From the slope of the best 


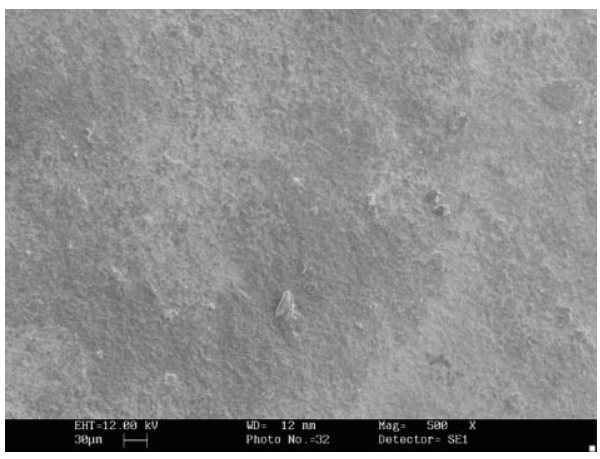

(a)

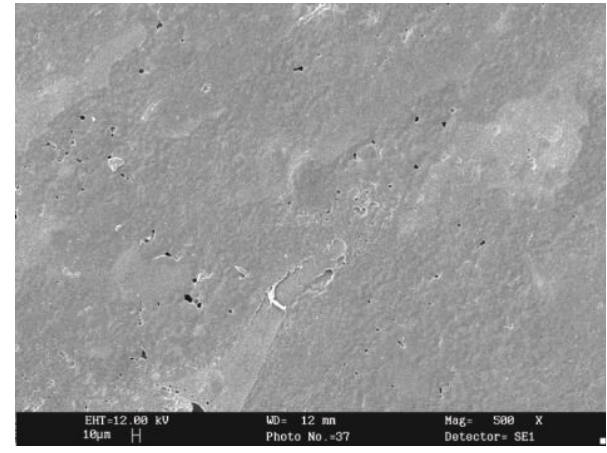

(b)

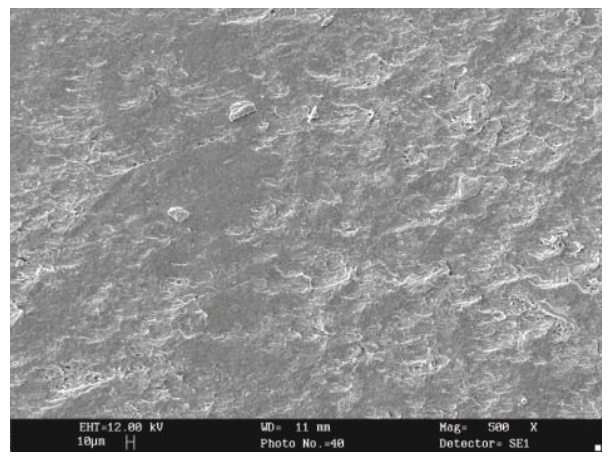

(c)

FIGURE 2: SEM micrographs of thin films of different compositions. (a) 100/0 PHBV/PLLA thin film; (b) 50/50 PHBV/PLLA thin film; (c) 10\% nHA in 50/50 PHBV/PLLA blend film.

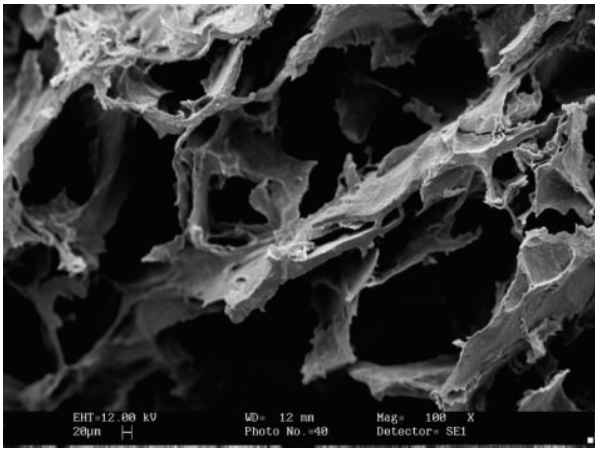

(a)

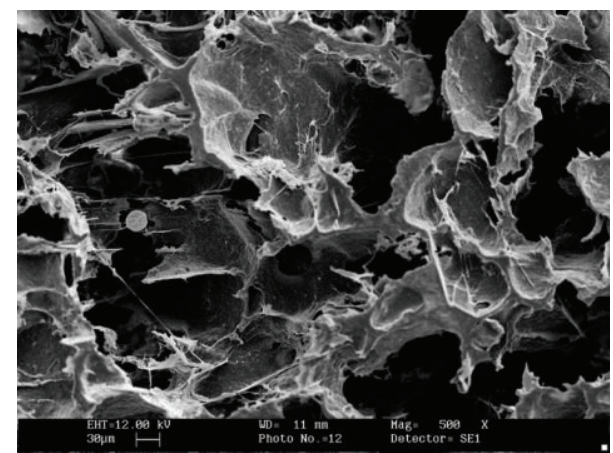

(b)

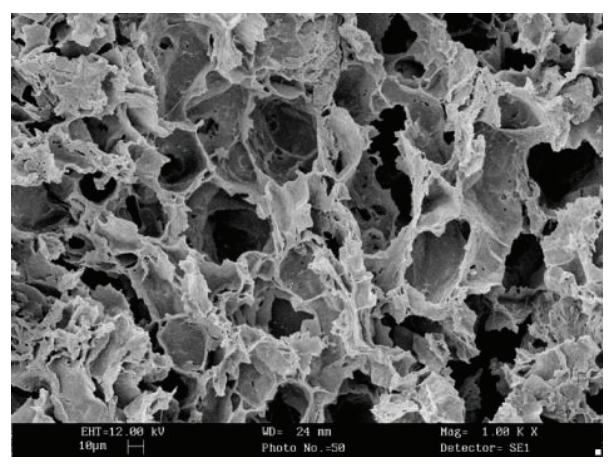

(c)

Figure 3: SEM micrographs of scaffolds of different compositions. (a) 100/0 PHBV/PLLA scaffold; (b) 50/50 PHBV/PLLA scaffold; (c) 10\% nHA in 50/50 PHBV/PLLA scaffold. 


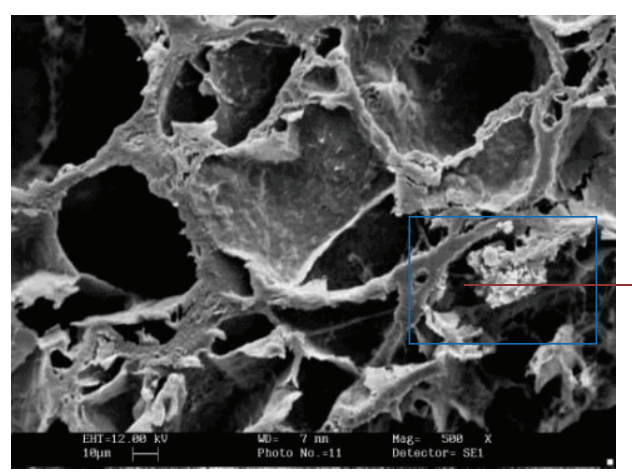

(a)

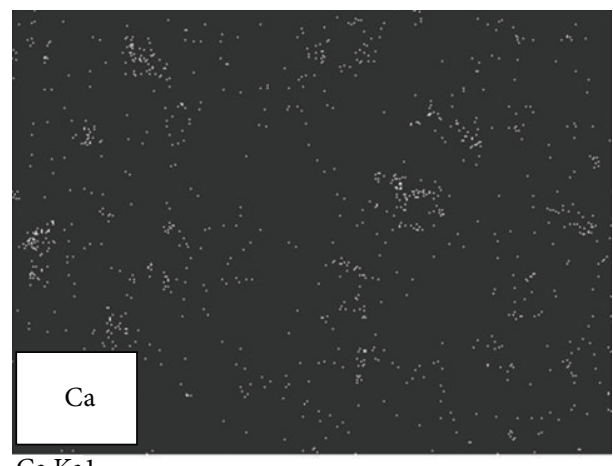

Ca Kal

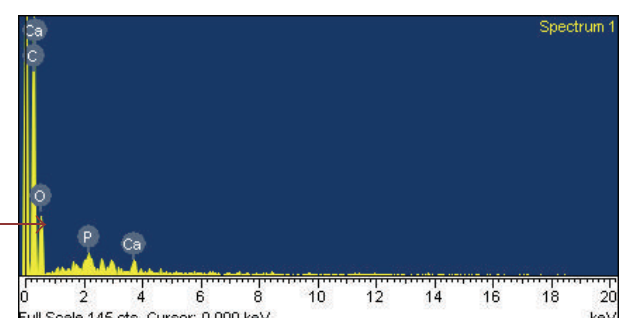

(b)

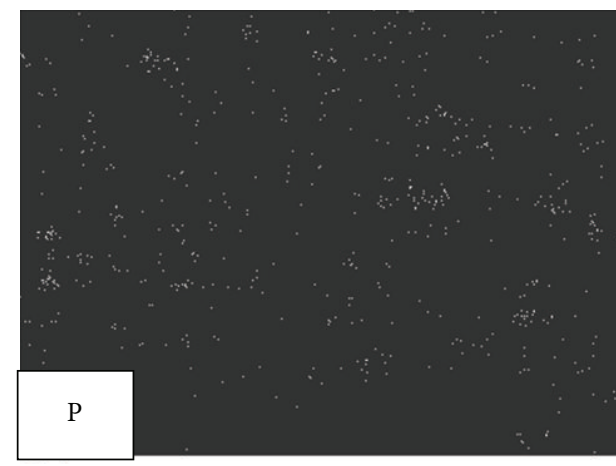

P Ka1

(c)

FIGURE 4: SEM micrographs of (a) 10\% nHA in 50/50 PHBV/PLLA composite scaffold; (b) EDX spectrum; (c) Mapping of Ca and P.

fit linear line, the activation energy was calculated, which was $100.9 \pm 5.3 \mathrm{KJ} / \mathrm{mole}$. The activation energies were found $120.3 \pm 45 \mathrm{KJ} / \mathrm{mole}$ for 50/50 PHBV/PLLA scaffold and $83.5 \pm$ $53 \mathrm{KJ} / \mathrm{mole}$ for 100/0 PHBV/PLLA scaffolds, respectively.

Table 4 shows the comparison between the amounts of water uptake $(\mathrm{g} / \mathrm{g})$ at equilibrium between the different compositions of thin films and scaffolds. Among the different compositions of thin films and scaffolds, the amount $(\mathrm{g} / \mathrm{g})$ of equilibrium water uptake of $10 \% \mathrm{nHA}$ in $50 / 50$ PHBV/PLLA films and scaffolds was higher than that of 100/0 PHBV/PLLA and 50/50 PHBV/PLLA thin films and scaffolds. This result was opposite to other studies where the uptake of HA/polymer composite films was slower than the pure polymeric film as the polymers were very much hydrophilic and water uptake was high for the polymer itself [12]. In the present study, it was also observed that water uptake increased significantly with the increasing porosity. The scaffolds which were more than $70 \%$ porous, absorbed more water at the same condition than that of dense films. Besides, the incorporation of HA increased the water uptake in both composite thin film and composite scaffold.

Water uptake can occur by the materials in terms of "absorbed water" that means the amount of water absorbed from media which mainly depends on the hydrophilicity of material. Capillary water is termed as liquid water that is "drawn in" through pores or capillaries of the materials. Moreover, the amount of water absorbed is related to the

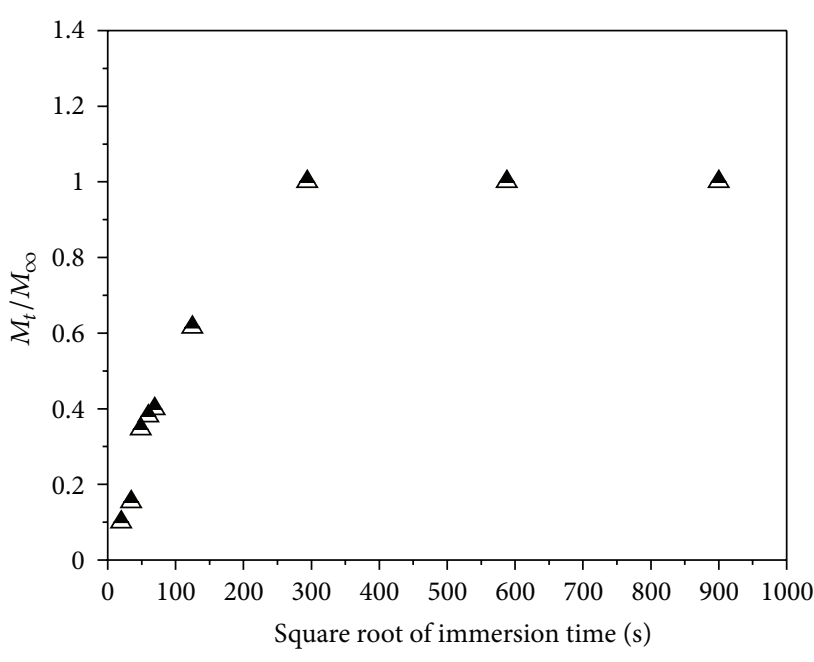

FIgURE 5: Water uptake curve for 100/0 PHBV/PLLA thin film at $37^{\circ} \mathrm{C}$ in the form of $M_{t} / M_{\infty}$ versus square root of immersion time.

porosity and the amount of available liquid water at the surface of the material. For this reason, porous material can uptake and store more water whereas the nonporous (dense) material can store a limited amount of water (Table 4). It can be seen from the plots of $M_{t} / M_{\infty}$ versus square root of time (Figures 5 and 7) that the plots are almost linear for both the 
TABle 2: Diffusion coefficients of thin films at $25^{\circ} \mathrm{C}, 37^{\circ} \mathrm{C}$, and $50^{\circ} \mathrm{C}$.

\begin{tabular}{lccc}
\hline Temperature $\left({ }^{\circ} \mathrm{C}\right)$ & $\begin{array}{c}100 / 0 \mathrm{PHBV} / \mathrm{PLLA} \text { thin films } \\
\left(\mathrm{m}^{2} / \mathrm{s}\right)\end{array}$ & $\begin{array}{c}50 / 50 \mathrm{PHBV} / \mathrm{PLLA} \text { thin films } \\
\left(\mathrm{m}^{2} / \mathrm{s}\right)\end{array}$ & $\begin{array}{c}10 \% \text { nHA in 50/50 PHBV/PLLA thin films } \\
\left(\mathrm{m}^{2} / \mathrm{s}\right)\end{array}$ \\
\hline 25 & $3.8 \times 10^{-13} \pm 1.5 \times 10^{-13}$ & $2.12 \times 10^{-13} \pm 0.65 \times 10^{-13}$ & $2.3 \times 10^{-13} \pm 0.7 \times 10^{-13}$ \\
37 & $11.3 \times 10^{-13} \pm 1.0 \times 10^{-13}$ & $3.215 \times 10^{-13} \pm 0.47 \times 10^{-13}$ & $11.6 \times 10^{-13} \pm 0.9 \times 10^{-13}$ \\
50 & $59.3 \times 10^{-13} \pm 12.0 \times 10^{-13}$ & $59.8 \times 10^{-13} \pm 3.53 \times 10^{-13}$ & $22.9 \times 10^{-13} \pm 0.8 \times 10^{-13}$ \\
\hline
\end{tabular}

TABle 3: Diffusion coefficients of scaffolds at $25^{\circ} \mathrm{C}, 37^{\circ} \mathrm{C}$, and $50^{\circ} \mathrm{C}$.

\begin{tabular}{lccc}
\hline Temperature $\left({ }^{\circ} \mathrm{C}\right)$ & $\begin{array}{c}100 / 0 \text { PHBV/PLLA scaffolds } \\
\left(\mathrm{m}^{2} / \mathrm{s}\right)\end{array}$ & $\begin{array}{c}50 / 50 \text { PHBV/PLLA scaffolds } \\
\left(\mathrm{m}^{2} / \mathrm{s}\right)\end{array}$ & $\begin{array}{c}10 \% \text { nHA in 50/50 PHBV/PLLA } \\
\text { scaffolds }\left(\mathrm{m}^{2} / \mathrm{s}\right)\end{array}$ \\
\hline 25 & $51.7 \times 10^{-12} \pm 1.1 \times 10^{-12}$ & $0.16 \times 10^{-11} \pm 0.06 \times 10^{-11}$ & $0.2 \times 10^{-11} \pm 0.05 \times 10^{-11}$ \\
37 & $67.6 \times 10^{-12} \pm 3.2 \times 10^{-12}$ & $3.58 \times 10^{-11} \pm 0.7 \times 10^{-11}$ & $1.3 \times 10^{-11} \pm 0.5 \times 10^{-11}$ \\
50 & $165 \times 10^{-12} \pm 9.1 \times 10^{-12}$ & $6.92 \times 10^{-11} \pm 2 \times 10^{-11}$ & $5.4 \times 10^{-11} \pm 1.35 \times 10^{-11}$ \\
\hline
\end{tabular}

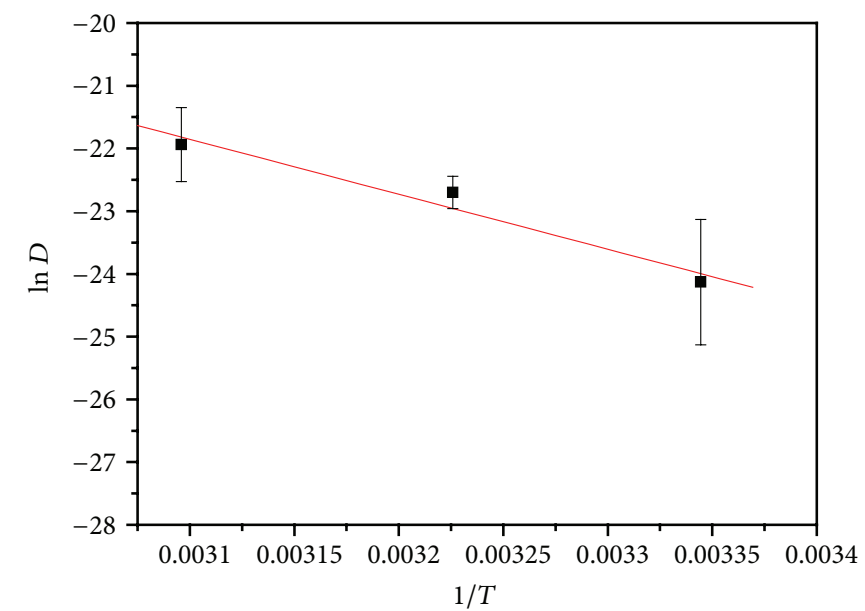

FIgURE 6: Arrhenius plot of 10\% HA in 50/50 PHBV/PLLA thin films (the graph is plotted as logarithm of diffusion coefficients $(D)$ versus the reciprocal of absolute temperature, $T$ ).

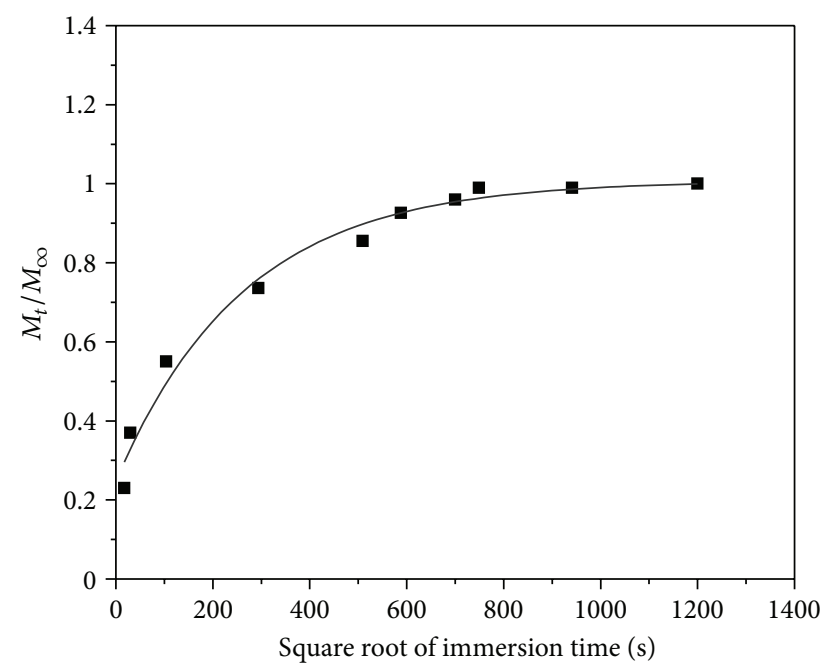

Figure 7: Water uptake curve for 100/0 PHBV/PLLA scaffolds at $37^{\circ} \mathrm{C}$ in the form of $M_{t} / M_{\infty}$ versus square root of immersion time.
TABLE 4: Comparison of equilibrium water uptake between thin films and scaffolds at $37^{\circ} \mathrm{C}$.

\begin{tabular}{lcc}
\hline $\begin{array}{l}\text { Compositions of films } \\
\text { and scaffold } \\
\text { specimens }\end{array}$ & $\begin{array}{c}\text { Equilibrium water } \\
\text { uptake for thin films } \\
(\mathrm{g} / \mathrm{g})\end{array}$ & $\begin{array}{c}\text { Equilibrium water } \\
\text { uptake for scaffolds } \\
(\mathrm{g} / \mathrm{g})\end{array}$ \\
\hline 100/0 PHBV/PLLA & 0.01 & 1.24 \\
50/50 PHBV/PLLA & 0.03 & 1.35 \\
10\% nHA in 50/50 & 0.09 & 2.97 \\
PHBV/PLLA & & \\
\hline
\end{tabular}

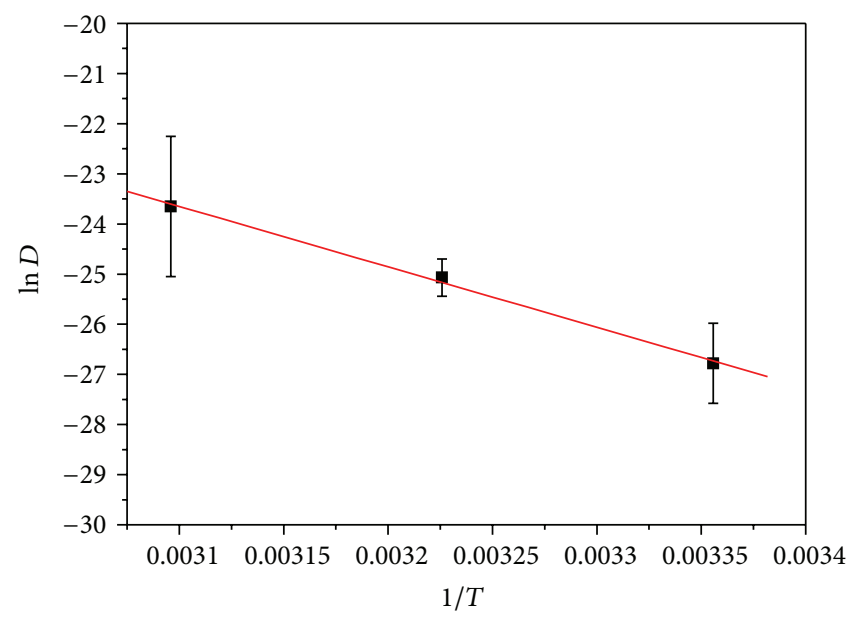

FIGURE 8: Arrhenius plot of 10\% HA in 50/50 PHBV/PLLA scaffolds (the graph is plotted as logarithm of diffusion coefficients $(D)$ versus the reciprocal of absolute temperature, $T$ ).

thin films and scaffolds in the initial period of time. As Fick's second law is applicable for both the thin films and scaffolds for the initial period of time, it can be stated that the initial stage is diffusion controlled. Similar results were obtained by several studies of polymeric composite materials for dental applications $[12,18,19]$.

It was also found that the water uptake of PHBV/PLLA scaffold was lower than $10 \mathrm{wt} \% \mathrm{nHA}$ incorporated $\mathrm{PHBV} /$ PLLA scaffold. For the scaffold specimens, when all the 
pores were assumed to be filled with water, the equilibrium water uptake of polymer blend scaffold and composite scaffold specimens were found to be $1.35 \mathrm{~g} / \mathrm{g}$ and $2.97(\mathrm{~g} / \mathrm{g})$, respectively (Table 4 ). Moreover, water uptake of composite scaffold specimen decreased after few days. The reason might be the starting of dissolution of nHA within the composite scaffold. The initial increase of water uptake of the composite films and scaffolds may be due to hydrophilic nature of the nanosized $n$ HA particles or the inclusions of HA nanoparticle aggregates. The nHA nano-particles may appear as loosely embedded aggregates in the polymer matrix. As a result, additional amount of water at the interface between the agglomerates and the matrix can be accommodated.

The calculated diffusion coefficients expressed are given in Tables 2 and 3 during water absorption. The values of diffusion coefficients are available in the literature for other conventional composites $[18,20]$. The diffusion coefficients were higher in scaffolds than thin films. This behaviour can occur during the initial uptake of water through the pores of the scaffolds which can cause the formation of water clusters. Surface area to volume ratio and thickness can also have effects on this.

Temperature and composition are the two most important factors which can affect the diffusion coefficient [21]. Between these two factors, temperature has the most profound influence on the coefficients and diffusion rates. The diffusion coefficients are related to temperature according to Arrhenius equation. From Arrhenius plots of thin film and scaffold (Figures 6 and 8), it can be seen that the plot is almost linear. These results can further confirm that water uptake of thin films is controlled by diffusion process. From the plots of $M_{t} / M_{\infty}$ versus square root of immersion time, it is also possible to estimate when a plateau region can be established and how long the diffusion phenomena can be observed. It was also found by other studies that after saturation, many other properties should be taken into account such as structure and surface chemistry.

\section{Conclusions}

(1) The amount of water absorption or uptake depends mainly on the hydrophilicity and porosity of the materials. For this reason, PHBV/PLLA and 10\% HA in PHBV/PLLA scaffolds and thin films absorbed more water than that of 100/0 PHBV/PLLA scaffolds and thin films as PHBV is more hydrophobic than PLLA and HA. The water uptake of the scaffolds was much higher than that of thin films because the scaffolds had high porosity.

(2) For thin films and scaffold, Arrhenius plot was almost linear. For the initial period of time, water uptake of the thin films was controlled by diffusion process. It was possible to estimate when a plateau region could be established and how long the diffusion phenomena could be observed.

(3) After saturation, many other properties should be taken into account such as structure and surface chemistry. 10\% HA in 50/50 PHBV/PLLA scaffolds showed decrease in water uptake after saturation due to dissolution of $\mathrm{HA}$ and also degradation of amorphous part of PLLA/PHBV polymer.

(4) The diffusion coefficients were higher in porous scaffolds than thin films as the rate of diffusion increased with decreasing density of atomic packing. Porosity and surface to volume ratio had a profound effect on the water uptake of scaffolds.

\section{Conflict of Interests}

The authors, hereby, declare that they do not have any conflict of interests.

\section{Acknowledgments}

N. Sultana thanks The University of Hong Kong (HKU) for providing her with a research studentship. This work was supported by a GRF Grant (HKU 7182/05E) from the Research Grants Council of Hong Kong. Assistance provided by technical staff in the Department of Mechanical Engineering, Faculty of Engineering, is acknowledged. Authors also thank Universiti Teknologi Malaysia, Ministry of Higher Education (MOHE), RMC, IJN-UTM Cardiovascular Engineering Centre, and FRGS Grant (vot: 4F126), GUP Tier 1 (03 $\mathrm{H} 13,05 \mathrm{H} 07)$ for financial supports.

\section{References}

[1] E. Bell, Tissue Engineering: Current Perspectives, Birkhäuser, Boston, Mass, USA, 1993.

[2] R. P. Lanza, R. S. Langer, and J. Vacanti, Principles of Tissue Engineering, Elsevier/Academic Press, Amsterdam, The Netherlands, 2007.

[3] Z. Li, Y. Su, B. Xie et al., "A tough hydrogel-hydroxyapatite bone-like composite fabricated in situ by the electrophoresis approach," Journal of Materials Chemistry B, vol. 1, no. 12, pp. 1755-1764, 2013.

[4] J. Lacroix, J. Lao, and E. Jallot, "Green and safe in situ templating of bioactive glass scaffolds for bone tissue engineering," Journal of Materials Chemistry B, vol. 1, no. 13, pp. 1782-1785, 2013.

[5] S. Lalan, I. Pomerantseva, and J. P. Vacanti, "Tissue engineering and its potential impact on surgery," World Journal of Surgery, vol. 25, no. 11, pp. 1458-1466, 2001.

[6] C. Bastioli, Handbook of Biodegradable Polymers, Rapra Technology, Shrewsbury, UK, 2005.

[7] E. Blümm and A. J. Owen, "Miscibility, crystallization and melting of poly(3-hydroxybutyrate)/poly(l-lactide) blends," Polymer, vol. 36, no. 21, pp. 4077-4081, 1995.

[8] N. Sultana and M. Wang, "PHBV/PLLA-based composite scaffolds containing nano-sized hydroxyapatite particles for bone tissue engineering," Journal of Experimental Nanoscience, vol. 3, no. 2, pp. 121-132, 2008.

[9] P. X. Ma, R. Zhang, G. Xiao, and R. Franceschi, "Engineering new bone tissue in vitro on highly porous poly $(\alpha$-hydroxyl acids)/hydroxyapatite composite scaffolds," Journal of Biomedical Materials Research, vol. 54, pp. 284-293, 2001.

[10] B. D. Ratner, BioMaterials Science: An Introduction to Materials in Medicine, Elsevier Academic Press, San Diego, Calif, USA, 2004 . 
[11] N. Sultana and T. H. Khan, "Factorial study of compressive mechanical properties and primary in vitro osteoblast response of PHBV/PLLA scaffolds," Journal of Nanomaterials, vol. 2012, Article ID 656914, 8 pages, 2012.

[12] M. Braden, "Water absorption characteristics of dental microfine composite filling materials. II. Experimental materials," Biomaterials, vol. 5, no. 6, pp. 373-375, 1984.

[13] S. Deb, M. Braden, and W. Bonfield, "Water absorption characteristics of modified hydroxyapatite bone cements," Biomaterials, vol. 16, no. 14, pp. 1095-1100, 1995.

[14] N. Sultana and M. Wang, "PHBV/PLLA-based composite scaffolds fabricated using an emulsion freezing/freeze-drying technique for bone tissue engineering: surface modification and in vitro biological evaluation," Biofabrication, vol. 4, no. 1 , Article ID 015003, 2012.

[15] W. Y. Zhou, M. Wang, W. L. Cheung, B. C. Guo, and D. M. Jia, "Synthesis of carbonated hydroxyapatite nanospheres through nanoemulsion," Journal of Materials Science: Materials in Medicine, vol. 19, no. 1, pp. 103-110, 2008.

[16] N. Sultana and M. Wang, "Fabrication of HA/PHBV composite scaffolds through the emulsion freezing/freeze-drying process and characterisation of the scaffolds," Journal of Materials Science: Materials in Medicine, vol. 19, no. 7, pp. 2555-2561, 2008.

[17] J. Crank and G. S. Park, Eds., Diffusion in Polymers, Academic Press, New York, NY, USA, 1977.

[18] M. Braden and R. L. Clarke, "Water absorption characteristics of dental microfine composite filling materials. I. Proprietary materials," Biomaterials, vol. 5, no. 6, pp. 369-372, 1984.

[19] C. Santos, R. L. Clarke, M. Braden, F. Guitian, and K. W. M. Davy, "Water absorption characteristics of dental composites incorporating hydroxyapatite filler," Biomaterials, vol. 23, no. 8, pp. 1897-1904, 2002.

[20] J. Crank and G. S. Park, Diffusion in Polymers, Academic Press, London, UK, 1968.

[21] R. E. Smallman and A. H. W. Ngan, Physical Metallurgy and Advanced Materials, Butterworth-Heinemann; Elsevier, Amsterdam, The Netherlands, 2007. 

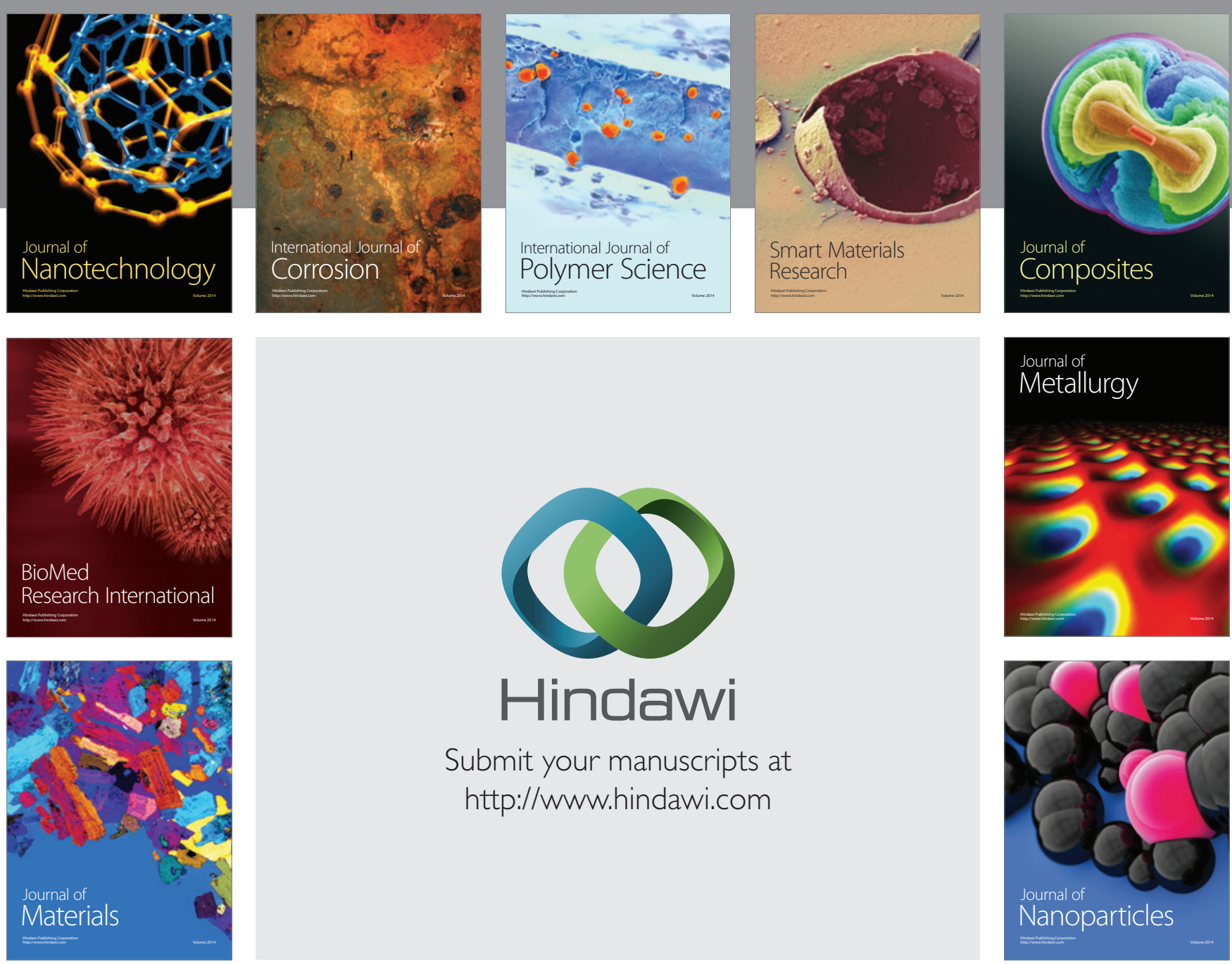

Submit your manuscripts at http://www.hindawi.com
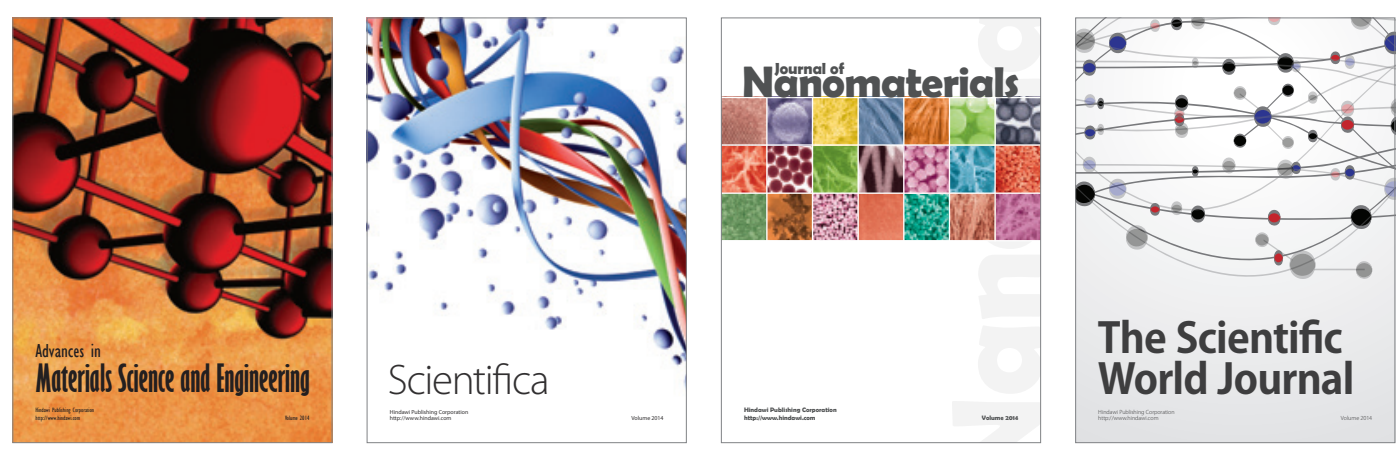

\section{The Scientific World Journal}
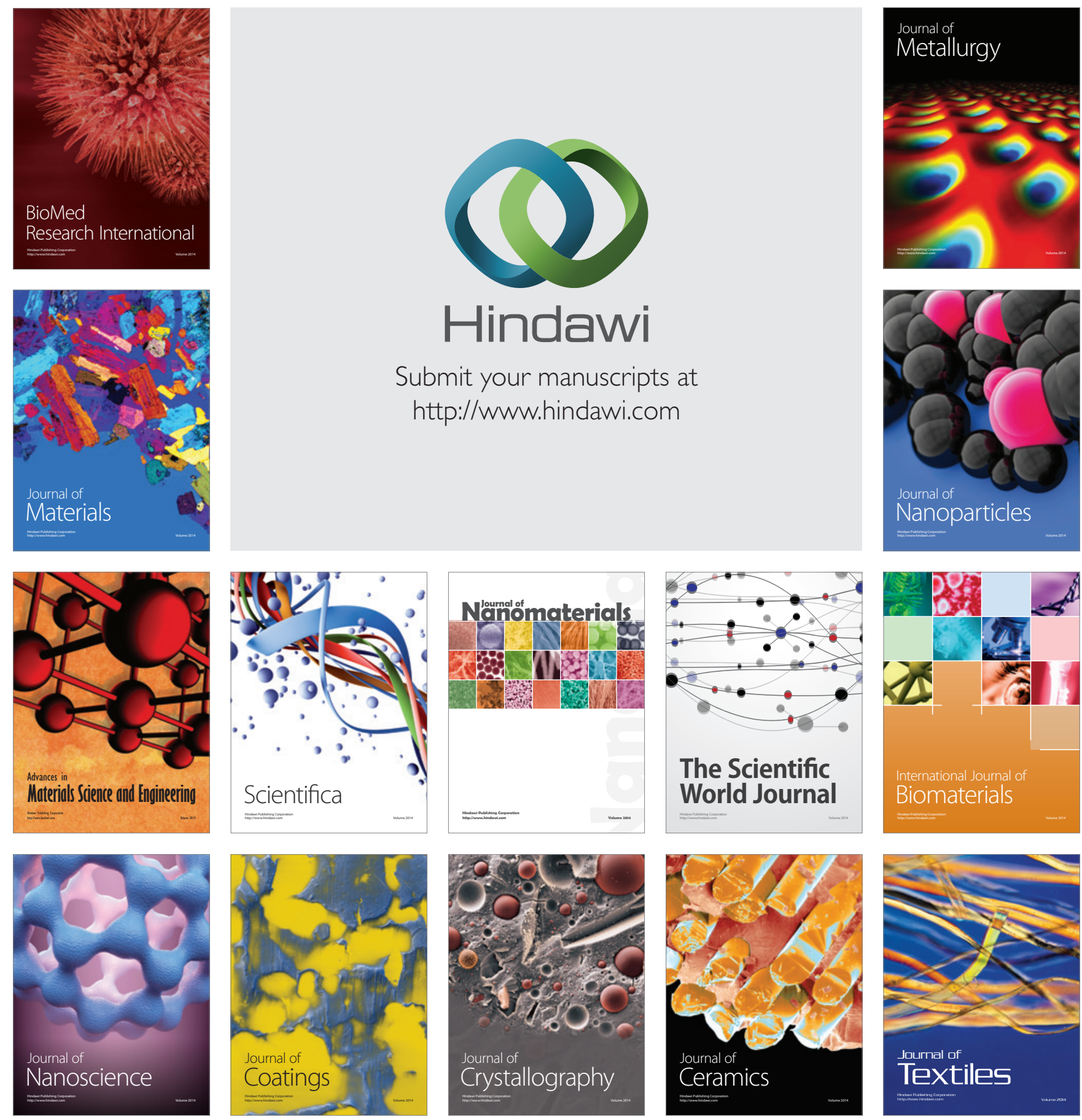